\title{
Reseñas de exposiciones
}

Manuel Munive Maco

Investigador independiente rupestrecontemporaneo@gmail.com

\section{EXOGÉNESIS \\ Muestra individual de Gloria Quispe. Galería del Hotel Sheraton}

La primera muestra personal de la grabadora bellasartina Gloria Quispe (Lima, 1990) constituyó uno de los mejores debuts a los que he podido asistir en los últimos años. Por la diversidad de formatos que integraban aquella nutrida colección de grabados, algunos realmente enormes, y por haber conjugado hasta tres diferentes técnicas de impresión en cada uno -algo que podía tomarse, incluso, como un alarde-, nos quedó claro que la autora llegaba a la escena artística local para enfrentar retos y que la gráfica tenía en ella a una de sus más tenaces exponentes jóvenes.

Pero por encima de todo lo dicho, el conjunto desarrollaba un programa iconográfico estéticamente coherente y ciertamente críptico: ¿qué quiso decir la artista con esas imágenes y esos personajes que,

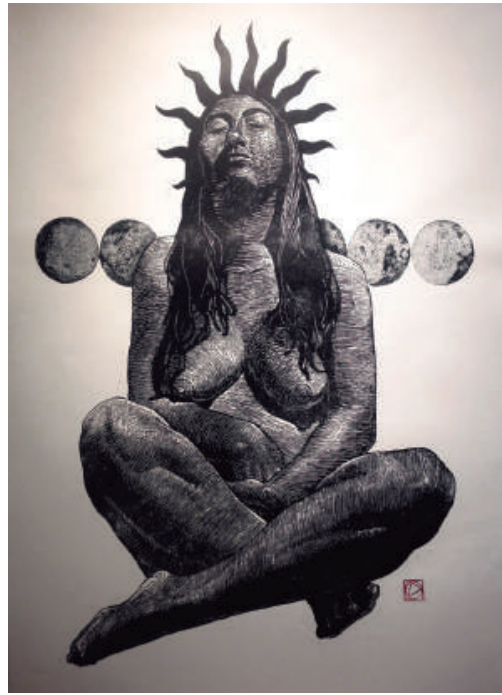

Gloria Quispe. Principio 1. Xilografía y colagrafía. $100 \times 70 \mathrm{~cm}$ formulados en clave realista, parecen aludir a una condición humana efímera, además de trágica? En todo caso, el título nos despistaba un poco, conduciéndonos a ámbitos como el de la astrobiología, alejándonos así del acertijo que configuraban aquellos personajes masculinos y femeninos que, desnudos y perplejos -o absortos- parecen levitar siempre en el centro del papel, asociados a geometrías secretas y animales cuyo significado fluctúa entre lo doméstico y lo simbólico. Porque en esta propuesta, la figura humana es central y protagónica, y eso, a la vez, requirió de un riguroso dibujo anatómico. Cada una de las piezas expuestas evidenciaba, en verdad, la gran autoexigencia desplegada por la autora.

Despojados de vestiduras, los personajes grabados de Gloria Quispe se liberan de cualquier atadura temporal precisa, demostrando que el desnudo suscita lecturas distintas en tiempos distintos.

Debo añadir, además, que asocio el notable trabajo de Gloria Quispe con la experiencia de haberlo descubierto en el hall del Hotel Sheraton, espacio que desde hace un tiempo ha sido habilitado como galería de arte, conquistando así un nuevo recinto expositivo para 
nuestro limitado circuito cultural. Creo, realmente, que en tiempos de clausura de galerías conviene que sean incorporados como espacios de contemplación sitios semejantes al del Sheraton, los cuales ya existen, y que por su ubicación pueden aproximar la experiencia artística a un público que vive completamente distante de los circuitos convencionales. Por eso, felicito a quienes gestionaron este espacio, deseando que se sostenga por mucho más tiempo y que sirva de modelo a otros más.

\section{DIEZ AÑOS DE XILOGRAFÍA}

\section{Luis Torres. Galería de Artes Visuales de la Universidad Ricardo Palma}

Debo empezar diciendo que organizar una exhibición antológica sobre el trabajo artístico realizado en el lapso de una década es válido en casos excepcionales, y que la trayectoria del grabador Luis Torres es lo suficientemente excepcional como para justificar la muestra inaugurada en la Galería de Artes Visuales de esta casa de estudios. Diez años de xilografía reunió lo más significativo de la producción de

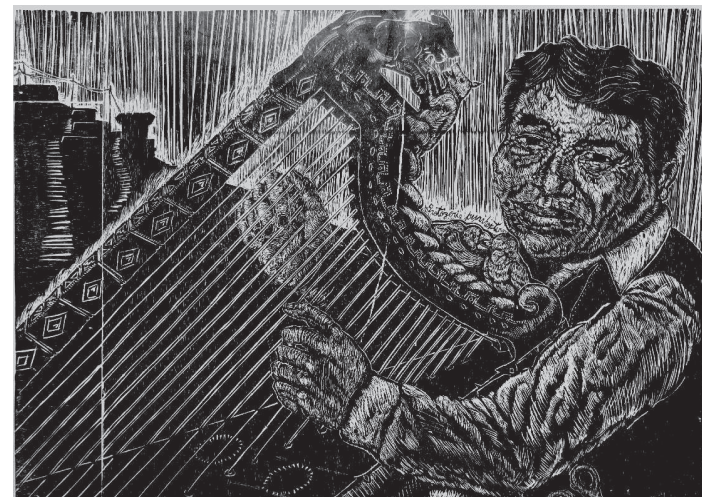

Luis Torres. Maestro Otoniel. Xilografía. 100 x 100 cm, 2015 este artista, que eligió el grabado en madera como medio de expresión estética (y ética).

El hito que marca el inicio de esta intensa labor xilográfica lo determinó el Primer Premio del 32. Salón Nacional de Grabado del Icpna, que Torres obtuvo el año 2008. El retrato áulico de aquel músico popular huanca, cuya riqueza iconográfica y gran formato determinaron, sin duda, la obtención de aquella distinción, contenía ya los postulados que han definido toda la producción xilográfica de esta primera década y, probablemente, de las que están por venir: me refiero a la particular asunción del ejercicio artístico con plena conciencia del lugar histórico que este ocupa, el cual, al ser particularmente xilográfico, adquiere en el Perú resonancias insospechadamente profundas.

Por suerte, aquella pieza memorable no fue "flor de un día” y, por el contrario, constituyó el preludio de una obra prolífica, compleja y tan persuasiva que ha revitalizado la xilografía peruana actual y ha estimulado su ejercicio entre artistas más jóvenes. Porque así como Carlos Runcie Tanaka marcó un hito para la cerámica contemporánea en la década de los ochenta, y la pintura de Christian Bendayán repercutió del mismo modo a fines de la década de los noventa, el ejercicio del grabado en madera es otro después de la incesante y febril labor de Luis Antonio Torres Villar.

Haber crecido muy cerca de las ruinas de una ciudad precolombina como la de Cajamarquilla tuvo que haberlo familiarizado desde muy temprano con lo arqueológico, y esa convivencia con los vestigios ancestrales debe haberlo dotado también de esa mirada, que le permite reconocer en el presente, reminiscencias del pasado, ya sea arcaico o colonial. Pero esa huaca, además, le demostró que en verdad somos criaturas pasajeras, que el Perú es un "país antiguo" -Arguedas dixit- y que, sobre el territorio de la ciudad que desde hace cinco siglos llamamos Lima, nacieron y murieron numerosas generaciones de individuos que nos cuesta incluso imaginar. 
Por otro lado, cuando Torres Villar realiza el retrato xilográfico del burilador de mates Sixto Seguil, no solo está continuando con su proyecto de registrar la fisonomía de un artista popular, tal como lo hizo con el saxofonista huanca del grabado premiado el 2008 -y con los otros cuatro miembros de la banda “Los Ángeles de Huancayo”, en el 2010-, sino que además tomó la posta sugerida hace más de setenta años por José Sabogal, cuando este retrata al otro célebre -y casi mítico- burilador, Mariano Inés Flores, a través del cual, el pintor cajabambino reconoce que si el ejercicio de burilar figuras y ornamentos en una calabaza, y el de tallar sujetos y objetos en un taco de madera comparten esencialmente los mismos instrumentos y parte del mismo proceso técnico, entonces eran de alguna manera "colegas".

Al reconocerse también colega del maestro Seguil, Luis Torres prolonga el camino de la xilografía peruana moderna abierto por los indigenistas. Y cuando en esta pesquisa descubre el notable mate de Huaca Prieta, cuya antiguiedad se estima en más de cuatro mil años, establece nuevos vasos comunicantes conceptuales y técnicos entre la xilografía, la plástica tradicional y la arqueología, convirtiéndolo en otro de sus motivos, como había hecho con los fardos funerarios y las ruinas.

Pero es justo y necesario destacar la apoyatura de la propuesta gráfica de nuestro artista en la exuberancia iconográfica de la pintura virreinal andina, así como en el hecho de que gran parte de esta se originó a partir de la reutilización o la reformulación de los grabados, principalmente flamencos, que llegaron al Perú en el equipaje de clérigos y artistas eruditos -tanto de las estampas en sí, como de las propias matrices-. Este referente explica la vocación de Torres por articular complejos -y, a veces, herméticos- discursos alegóricos mediante elementos visuales del medio pictórico colonial como "rompimientos de gloria", cartelas, filacterias, etc. Es en estas piezas que el artista alude a la silenciosa supervivencia del pensamiento andino en el presente, algo que no puede concebirse sino como resultado de una larga resistencia cultural.

Las dimensiones de sus obras - una de las cuales llega a medir 200 x $200 \mathrm{~cm}$ - se ven justificadas por la densidad de la información visual inscrita en cada una. Debo confesar que hasta hoy no termino de ver ninguna de estas grandes xilografías, pues la mirada se distrae entre los numerosos personajes y elementos que pueblan esas locaciones o escenarios, tal como sucede con los universos miniaturizados y encerrados en un cajón de San Marcos o un retablo ayacuchano.

Sin duda, en los grandes grabados, como A los mismos instantes del terremoto (2009), en donde transfigura en donantes virreinales a una familia de atemorizados pisqueños que rezan durante el terrible sismo de 2007; y especialmente en Los frutos de tu envidia, Subida y Arpa, que integran la serie Reconquista (2010), la cual se ha inspirado en los paneles de la serie cusqueña dieciochesca del Corpus Christi, es donde el joven grabador evidencia esa pulsión por dotar de un rostro verosímil -de una identidad- a cada uno de los personajes que los pueblan, aun cuando estos se encuentren dentro de un grupo numeroso y abigarrado. En estas imágenes, el sujeto y su entorno forman una unidad indivisible.

Y esa peculiar relación entre el grabado europeo y la pintura virreinal, fenómeno exclusivo de nuestra historia del arte, puede detectarse incluso en el modo en el que Torres Villar concibe su producción gráfica: no hace ediciones, como lo exige la disciplina de la multicopia, sin duda porque en el caso de sus grandes obras -semejantes a grandes cuadros- es muy difícil encontrar en el mercado local pliegos de papel a la medida, y porque tampoco hay coleccionistas que lo inciten; pero, sobre todo, porque lo que a él le importa es realizar el taco, grabar la matriz y preservarla, imprimiéndola de cuando en cuando, haciendo del proceso de impresión un ritual infrecuente, no seriado, como una pintura. Y si consideramos que cada una de sus composiciones tuvo que ser grabada a la inversa, "en espejo", 
para que resulten impresas tal cual las vemos, podemos llegar a concebir este proceso como una penitencia. (Más de una vez él ha elaborado artesanalmente un pliego de papel sobre el cual imprimió un ejemplar).

La arqueología, la antropología, la etnohistoria y la historia del arte ofrecen métodos que nos ayudan a desentrañar "esto que somos". La obra gráfica de Luis Antonio Torres Villar se sirve de todas ellas y de su memoria -familiar, barrial, distrital, capitalina, provinciana, nacional-, para ofrecernos estas visiones que reconstruyen, restauran, retratan, interpretan, inventan y sueñan el Perú, ese "país antiguo" en el que todas las épocas coexisten, en donde los vivos y los muertos integran una colectividad y mantienen todavía deudas mutuas por saldar.

\section{CUERPOS EN SILENCIO}

\section{Exposición antológica de Anselmo Carrera. Centro Cultural de Bellas Artes}

¿Qué tan contundente debe ser una obra para que, expuesta con deficiencias de montaje y vacíos cronológicos ostensibles sea, sin dudarlo, una de las mejores exposiciones del año y la mejor que en mucho tiempo se presenta en la museográficamente apática -cuando no hostil- galería del Centro Cultural de la Escuela Nacional de Bellas Artes?

Cuerpos en silencio fue el título de esa muestra antológica que ha rescatado del olvido inminente la obra de Anselmo Carrera (Lima, 1949-2016), uno de los mejores artistas egresados de la ENBA y uno de

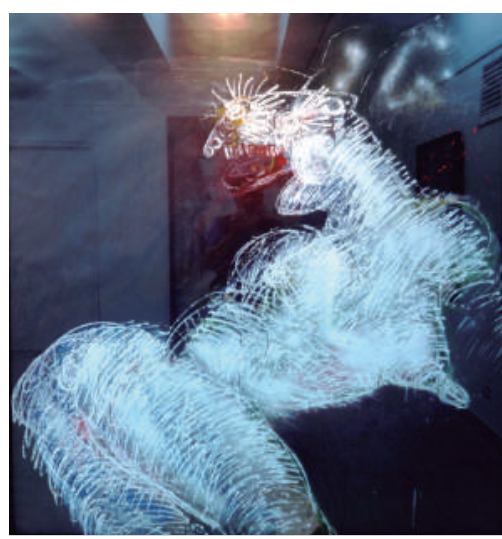

Anselmo Carrera. Sin título. Técnica mixta los pocos que, por su destacada trayectoria, mereció dirigirla, preservando así la tradición de excelencia que había caracterizado a quienes ejercieron ese cargo durante el siglo pasado, y que fue tan necesaria de recuperar, precisamente ahora que la institución cumple su primer centenario.

Carrera falleció hace dos años, pero por lo menos hacía veinte que había abandonado las salas de exposición para concentrarse en realizar una prolija y silenciosa labor docente en su alma máter. Recuerdo el caso de un artista joven que fue su alumno y se enteró por mí acerca de la trascendencia artística de ese serio -y secreto- profesor de los cursos de Dibujo y Aerografía. ¿Carrera había decidido borrar cualquier evidencia sobre su trayectoria de pintor y notable gráfico? Puede sonar exagerado, pero esa es la impresión que al final me dejó. Por eso, imagino que debió estar conforme cuando se le excluyó de la nómina de artistas peruanos fallecidos ese infausto 2016, publicadas en algunos periódicos locales.

Su participación en la muestra grupal Cuatro pintores jóvenes, organizada por la Galería Fórum en 1975, es la primera consignada en algunos de sus catálogos, los mismos que nos permiten aseverar que entre 1979 y 1982, en la misma galería miraflorina, inauguraría sus cuatro primeras muestras personales. A ese periodo corresponden también sus primeros reconocimientos internacionales, como los que obtuvo en Colombia en 1981: el Primer Premio de Dibujo en la 4. ${ }^{a}$ Bienal Americana de Artes Gráficas del Museo de Arte Moderno "La Tertulia", en Cali, y su incorporación al portafolio de serigrafías Cinco Jóvenes Pintores Latinoamericanos, editado e impreso por la Corporación Pro Gráfica de la misma ciudad colombiana. 
En 1982 participaría en la Bienal Gráfica Internacional de Noruega y, posteriormente, en la 5. ${ }^{a}$ Bienal de Dibujo de Maldonado (Uruguay); en la 8. ${ }^{a}$ Bienal Británica de Grabado de Bradford (Inglaterra, 1984); Intergrafik 84, Berlín del Este (Alemania, 1984); la 3. ${ }^{\text {a Bienal de }}$ Cuenca (Ecuador, 1991); la Trienal de Grabado de Finlandia, 1993; y Arte Contemporáneo del Perú en el Museo José Luis Cuevas (México, 1996).

La pieza más antigua presentada en Cuerpos en silencio data de 1979 y es probable que haya formado parte de la serie que integró Tintas sobre tela, su primera individual de ese año en Fórum. En esa pieza sin título, veremos el tema que será recurrente en todo su trabajo. Me refiero a la silueta de la figura humana y, particularmente, la sección del cuerpo que abarca la cabeza y el vientre, el cual, resuelto en diversas técnicas y en una creciente y visceral intensidad, jamás cae en la monotonía; por el contrario, deja en claro que estamos ante el asedio sistemático y en profundidad de una idea.

Encontramos también en la muestra del Centro Cultural de Bellas Artes, trabajos realizados entre 1980 y 1982, así como la presencia notoria del medio serigráfico en técnicas mixtas de 1984 y algunas experimentaciones de 1990, específicamente de la lograda y críptica serie El Frontón. Debo subrayar que, en 1987, obtuvo la Beca de la Fundación Reed para el Programa Fund for Artists, en los Estados Unidos, pero al parecer no se ha podido recuperar el trabajo ejecutado bajo ese auspicio. Cierran la cronología, dando un salto de ocho años, los dos cuadros que nuestro artista preparó exclusivamente para la Bienal de Lima de 1998, los cuales ostentan un colorido luminoso e inédito que justificaba que permaneciéramos expectantes de su trabajo.

Lamentablemente, entre ese año y su fallecimiento nunca volvió a exponer una individual y participó en pocas muestras colectivas, como aquella antológica que curé en el año 2002 y se montó en la Municipalidad de Miraflores, bajo el título "Mesa de luz. Breve historia de la serigrafía en Lima”. Durante la conversación de coordinación que sostuvimos aquella vez dejó en claro que su experimentación en serigrafía se produjo exclusivamente a partir de su paso por la Corporación Pro Gráfica de Cali.

Pero si bien no pude ver ninguna exhibición individual de Anselmo Carrera, empecé a encontrarme frecuentemente con él visitando las exposiciones de otros a lo largo de esos veinte años de silencio creativo. Es gracias a esos numerosos encuentros, generadores de breves diálogos, que puedo decir que lo conocí y a partir de los cuales me proporcionó algunos catálogos y diapositivas que me sirven ahora para hacer este accidentado recuento ${ }^{1}$. (Curiosamente es probablemente el único artista y docente con el que he coincidido con tanta regularidad en galerías).

Como en el caso de Johanna Hamann, para la escultura, el trabajo plástico y gráfico de Carrera pareció prefigurar la violencia terrorista que signó al Perú durante las últimas dos décadas del siglo pasado. ¿Qué caracterizaba su estilo? Carrera plasmaba fundamentalmente agredidos cuerpos humanos masculinos llevados al borde de la desintegración, muchos de ellos a escala humana, con los cuales erigió un lenguaje personal cuyos ecos expresionistas reconocemos reelaborados inteligentemente en el trabajo de artistas tan destacados como Jorge Castilla-Bambarén, Eduardo Tokeshi y Marco Alburqueque, por ejemplo.

Profundidad temática y una lograda experimentación técnica conjugadas para hablar de la violencia, sin caer en clichés; para hablar de los muertos a consecuencia de esa violencia,

1 La entrevista más larga que me concedió se realizó a mediados de 2010 en un chifa de Santa Beatriz, frente al Centro Cultural de España. En esa ocasión, me permitió fotografiar la carpeta de fotocopias, dibujo y pintura que, bajo el título de Cuaderno 1, había presentado en la 5. ${ }^{a}$ Bienal Americana de Artes Gráficas de Cali, en 1985. En ese momento tenía a mi cargo un curso de Historia del grabado peruano en el Departamento de Grabado de la Facultad de Arte de la PUCP, y usé ese material para una de mis clases. 
sin servirse de la fotografía de esos muertos; de la dificultad para distinguir a unos de otros en medio de las sombras; de la posibilidad de que el espectador sospechara que podía convertirse azarosamente en un desaparecido, como aquellos cuyas siluetas torturadas penan en sótanos de insondable oscuridad; de lo circunstancial que ha determinado que nosotros sigamos vivos.

Si en el trabajo temprano de Carrera distinguimos una primera influencia de José Luis Cuevas y, posteriormente, se evidencia la huella de una lección baconiana más rotunda, es innegable que arribó a instancias inéditas de ese expresionismo ominoso mediante una inteligente reelaboración personal. Destaco en Cuerpos en silencio esas dos obras en gran formato que representan mujeres blancas desnudas, resueltas con acrílico, aplicado directamente del chisguete y con aerosoles, además de esas raspaduras lacerantes de la superficie pictórica que caracterizan su estilo.

Creo que la valía de la obra de un artista se aprecia realmente cuando este ha fallecido y cae en manos de terceros la responsabilidad de su recuperación como patrimonio común. Parece que la obra de Anselmo Carrera ha emprendido, felizmente, ese infrecuente proceso.

\section{PAISAJE MÍTICO}

\section{Susana Aguilar. Sala de El Cultural, Trujillo}

Hace poco, y en son de broma, me arriesgué a decir que existen dos tipos de artistas: aquellos a los que les gusta trabajar y aquellos a los que les gusta exponer. Agregué que los primeros trabajan permanentemente porque son autocríticos y llegan incluso a dudar de que son artistas; mientras que los segundos creen que lo son simplemente porque exponen. Rematé mi ocurrencia afirmando que los primeros se hacen extrañar; mientras que los otros pueden llegar a hartarnos de verlos demasiado frecuentemente en galerías. Ahora que me corresponde reseñar la muestra individual de dibujo de Susana Aguilar, veo que esa aparentemente arbitraria clasificación tiene algo de validez, y que ella no solo pertenece al primer grupo, sino que -debo admitirlo- pensaba en artistas como ella cuando se me ocurrió.

Susana Aguilar (Trujillo, 1980) es una joven pintora liberteña que, a pesar de los reconocimientos obtenidos, desapareció repentinamente -al menos en

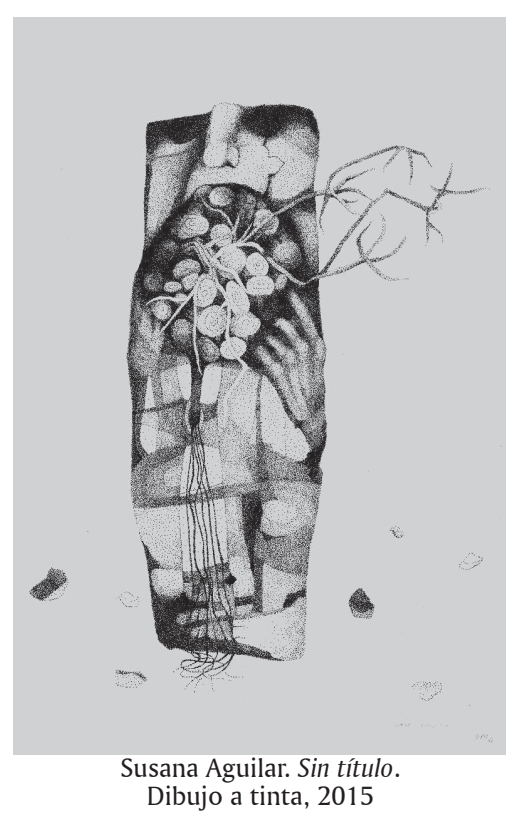
Lima-, cuando apenas empezábamos a apreciar y a disfrutar de sus cuadros. En aquellos, recuerdo que no solo encontrábamos una propuesta de alta calidad pictórica, sino también un imaginario complejo, resultante de su original y clarividente mirada sobre el mundo que la rodea: en esas pinturas quedaban revelados, a su vez, otros mundos paralelos e interconectados mediante el paisaje, el cosmos y la memoria ancestral.

En esta ocasión, la artista ha reunido una nutrida colección de dibujos resueltos en la rigurosa -y paciente- técnica puntillista. En varios de ellos reconocemos algunos de sus temas predilectos, específicamente sus visiones del paisaje desértico o pétreo, y su ingente 
potencial mítico. En otros ha dotado de una fisonomía a la pachamama y al viento, o ha insuflado de vida a algunas de las encarnaciones plásticas más tempranas de la ideología andina, como son la huanca y la estela. Y es en los dibujos coloreados donde nos queda claro que la ilustración tiene en Aguilar un exponente dotado como pocos. Algunas piezas, como la de El Colibrí, Yacana y La comunión de Kametza y Naroué, por ejemplo, parecieran desde ya las primeras láminas de un libro ilustrado que urge reescribir. Debo agregar que en este conjunto aparecen también sus primeras indagaciones en el casi infinito campo de la cosmogonía amazónica.

Durante la década que ha transcurrido sin verla exponer ni individual ni colectivamente, me preguntaba qué sería de ella y por qué los buenos artistas de pronto deciden que no nos hacen falta. Claro que siempre me la imaginé trabajando, discretamente, como estos bellos y delicados trabajos lo demuestran. Por eso he celebrado esta reaparición. Ojalá que no nos haga esperar otros diez años.

NEO IMAGINARIO ARCAICO

Alberto Ramos. Centro Cultural de la Universidad San Agustín, Arequipa

¿De qué modo la lengua materna de un artista plástico influye en su manera de elaborar un imaginario visual propio? ¿Es posible que un creador que aprendió primero lo que hoy conocemos como una "lengua originaria" pueda acceder con mayor facilidad a una suerte de "memoria ancestral de imágenes”? ¿Y esto se puede percibir a primera vista? Estas y otras preguntas semejantes me rondan desde hace tiempo, prácticamente desde que conocí el trabajo de Alberto Ramos Palacios, uno de los xilógrafos peruanos más importantes. Como puede deducirse por la peculiar sonoridad de los nombres que el artista confirió a los pequeños grabados que integran esta exposición individual -Challwa, Huaylis, Jiwar, Shuspi, etc.-, su primera lengua es el quechua. Y no cabe duda de que el runa simi permite que designemos más afectuosamente a los seres y las cosas.

Siempre me ha parecido que algo de esa memoria cultural asoma con particular naturalidad en el trabajo de Ramos Palacios, específicamente en la morfología de sus criaturas, la cual parece extraída de

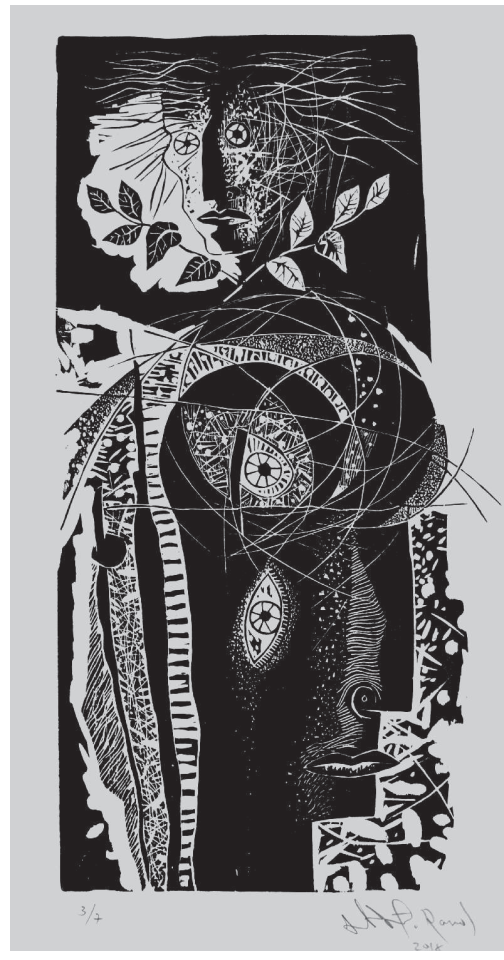

Alberto Ramos. Autoretrato. Xilografía. $10 \times 20 \mathrm{~cm}, 2018$ una recién descubierta tradición plástica rupestre, una de aquellas inmemoriales expresiones grabadas en roca que permanecen a la espera de incorporarse al lenguaje de los grabadores contemporáneos del Perú. Pero también puede reconocérsele en su tendencia a apaisar sus composiciones, planteando así piezas rectangulares que, por su longitud, pueden tomarse por calcos de la iconografía ornamental de alguna vasija cerámica, de un friso pétreo o de un textil.

Albero Ramos Palacios nació en Nasca, Ica, en 1953. Realizó estudios de Pintura, Dibujo y Grabado en la Escuela Nacional de Bellas Artes del Perú entre los años 1976 y 1991. Obtuvo 
el Primer Premio del XXII Salón Nacional de Grabado del Icpna en 1987; el Primer Premio de la III Bienal Internacional de Gravat, Contratalla, Ex Libris (España) en 2006; el Tercer Premio Ex Libris de la Trienal Iberoamericana de Grabado, Xylon, Argentina y el Primer Premio del V Kiwa Exhibition (Japón) en 2007. Desde hace más de una década se desempeña como docente de la Escuela de Formación Artística Pública "Francisco Laso", en Tacna.

Neo Imaginario Arcaico, la octava muestra individual de este artista, está conformada por una veintena de pequeñas xilografías realizadas entre los años 2010 y 2018. Las criaturas imaginarias que habitan dichas estampas conforman un bestiario mítico singular en el que una carismática fauna menor, constituida básicamente por aves, serpientes e insectos, que coexisten, combaten y se confunden, emerge de aquel "chisporroteo" gráfico que es la marca inconfundible de nuestro artista, y el cual le otorga ese halo de acontecimiento mágico -o sobrenatural- a cada una de sus escenas.

Así como me entusiasmó conocer su grabado titulado Huallallo, el dios devorador, el cual constituye la primera entrega de ese ambicioso proyecto de ilustrar o visibilizar mediante la xilografía a las deidades del enrevesado texto quechua del siglo XVI que conocemos como el Manuscrito de Huarochirí, considero que estas criaturas que hoy contemplamos reclaman también una narrativa textual que las hilvane. Esto me parece particularmente imperioso en el caso del grabado llamado Cocaquinto, el cual retrata a una serpiente ornitomorfa cuyas cinco alitas son, en verdad, cinco hojas de coca, como si se tratase del resultado de un cruce entre fauna y flora. Puede que esa sea otra de las virtudes del trabajo de este notable xilógrafo peruano: obsequiarnos la posibilidad de gestar mitologías entrañables.

\section{OPERACIÓN AYAR \\ Muestra antológica de Julio Camino Sánchez. Sala del ICPNA de San Miguel}

Los artistas plásticos incursionan poco en el grabado $\mathrm{y}$, si lo hacen, le confieren un lugar marginal dentro del conjunto de su obra a las estampas que han producido. Esta actitud la explica, seguramente, la idea errónea de considerar a la obra multicopiada como un "arte menor", la cual, a su vez, se apoya en el hecho de que una xilografía o una litografía resulta muchísimo más barata que un cuadro y que, entre nosotros, es más rentable socialmente jactarse de comprar pinturas que grabados. Pero también pesa en esa postergación de la propuesta gráfica en nuestro medio el que esta requiera de insumos e instrumentos que hasta hace muy poco eran difíciles de conseguir en Lima y, sobre todo, que no aparezca hasta hoy un marchante que avizore que allí hay un nicho comercial latente desde hace décadas.

Julio Camino Sánchez (Trujillo, 1914-Lima, 2007) puede ser una de las pocas excepciones a esa regla equívoca -otra excepción la constituye Luis Solorio-, pues si bien fue un pintor académico, dedicó al grabado un

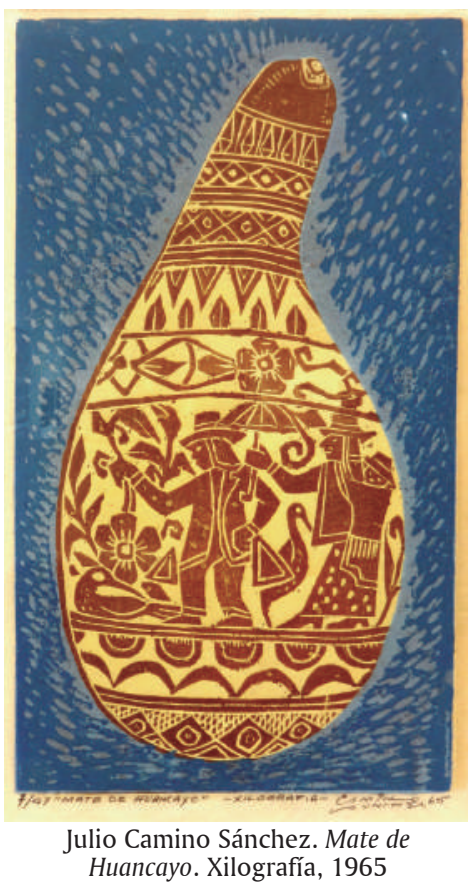
espacio enorme dentro de su trabajo creativo personal y fue, sin duda, revolucionario en 
otro campo que los artistas rehúyen hasta que las urgencias económicas los conminan: la enseñanza del arte en la escuela.

Conocí a Julio Camino Sánchez en 1997, durante la noche inaugural de la exposición de la colección de José A. Fernández, su gran amigo y admirador, en el Museo de Arte de San Marcos, la cual incluyó un par de piezas de su autoría. Fue justamente en la casa de ese coleccionista, que descubrí de golpe unas sesenta o setenta xilografías y unos pocos óleos de Camino Sánchez repartidos por todas las habitaciones y, en especial, un pasadizo en el que uno se sentía acorralado por estampas. José A. Fernández había publicado en 1995 un libro dedicado a los grabadores peruanos, que me reveló el trabajo de xilógrafos tan notables como Teófilo Allaín, Carlos Bernasconi o el propio “Julito”, que era como él solía llamarlo.

Solo cuando supe que era un xilógrafo autodidacta empecé a sospechar por qué hacía más grabados que óleos, aun cuando era un pintor solvente y se había formado en la Escuela Nacional de Bellas Artes bajo la enseñanza de José Sabogal y dentro de la efervescencia indigenista en ese centro de formación. Mi sospecha era que la xilografía era una técnica que había conquistado por su cuenta, experimentando desde niño y eso la convertía en su medio predilecto de creación. Recordemos que, prácticamente, desde que estaba en el colegio colaboró ilustrando ediciones de los diarios La Industria y La Nación de Trujillo. Es evidente que no llegó a Lima para empezar de cero.

Esta sospecha ha sido afianzada mediante Operación Ayar, la estupenda exposición antológica del artista trujillano en la sala del Icpna de San Miguel. Si bien Camino Sánchez disfrutó de celebridad en vida y ha motivado ya una muestra antológica póstuma en la Asociación Cultural Peruano Británica, es la primera vez que se organiza una exhibición dedicada exclusivamente a su copiosa producción xilográfica. Y lo más trascendental: esta muestra ha dejado un volumen ilustrado con alrededor de 140 xilografías -sin contar los abundantes "tacos" o matrices-, cuya autoría recae en Gabriela Tineo y Javier Rodríguez. Este libro permite conocer de una sentada lo más substancial de esa obra inmensa.

Me parece que todas las temáticas que Camino Sánchez realizó en xilografía estaban allí representadas, tanto retratos verosímiles o imaginarios, estampas del paisaje y la arquitectura norteña, así como abstracciones y, en particular, sus sistemáticos asedios a los especímenes de la plástica precolonial y tradicional peruanas, evidentes en sus estampas sobre la cerámica escultórica Recuay, los geoglifos de Nasca o las iglesias alfareras de Quinua, así como esos mates burilados, tan próximos al grabado en madera, que contienen narrativas figurativas del mundo campesino y rural andino. Y, por supuesto, encontramos también algunas estampas de Operación Ayar, aquella serie de 1969, permanentemente "abierta", y en la que el artista trujillano conjugaba motivos provenientes de la iconografía cultural peruana y elementos propios en audaces soluciones compositivas. Pero ¿qué quiso decirnos al usar la palabra "Ayar", la cual nos remite a uno de los mitos de origen de nuestra cultura ancestral, en el título de ese proyecto más personal? (Señalo que era una serie abierta porque grabados amparados bajo ese título solían aparecer en diversas exposiciones, como -lo acabo de ver-sucedió en una muestra de 1976 presentada en la Galería Trapecio.)

Julio Camino Sánchez parece ser uno de aquellos artistas peruanos que, en diferentes momentos, recorren en soledad un camino que los conduce hacia el pasado mediante los especímenes arqueológicos y hacia las repercusiones de ese pasado en el presente, embozadas en las expresiones populares, tal como lo hicieron Elena Izcue y Alicia Bustamante, por ejemplo. Un tipo de artista cuya sensibilidad no le permite soslayar las formas visibles de la cultura heredada y la incorporan a su búsqueda de por vida.

Y aquella estimulante experiencia de trabajar con acervos de formas plásticas peruanas la compartió en los colegios donde trabajó con una dedicación ejemplar, como lo comprueba 
el mural sobre Manco Cápac y Mama Ocllo, que en 1958 realizó junto a sus alumnos de la Gran Unidad Escolar "Bartolomé Herrera”; pero, sobre todo, los cuadernos de dibujo que diseñó y mandó a imprimir en 1944 -dentro del estilo de los que en 1925 editó Elena Izcue-, los cuales reproducían motivos Moche o conopas alfareras de Ayacucho, con los cuales los estudiantes de Secundaria podrían ejercitarse. El tiempo que le dedicó a la enseñanza escolar le restó mucho al ejercicio de su propia obra. Sin embargo, expuso en diversas partes del mundo, como lo consigna la lista de sus muestras individuales en Chile, Ecuador, Brasil y España.

¿Por qué no encontramos en su pintura ni la mitad de temas que nuestro artista grabó en madera? Porque, ahora lo veo con más claridad, su indagación con pincel sobre tela no habría sido tan exploratoria como lo fue tallando "a la inversa" cada uno de los motivos que eligió transcribir o recrear. Además, el pincel y el óleo constituyen un medio venido de otro mundo, mientras que el grabado, es decir, la incisión sobre una superficie, tal como lo testimonia la plástica rupestre andina -o el mismo mate burilado- es un medio más nuestro.

Por eso, Julio Camino Sánchez confió a la xilografía sus experimentaciones más libres y poéticas, las cuales eran también las operaciones intelectuales más complejas y originales de su obra. Nuestro artista viajaba por el tiempo, yendo y viniendo por los caminos de la plástica precolombina y del arte tradicional peruanos usando la xilografía como la llave o salvoconducto de ese periplo, largo, incierto e imborrable. 